\title{
ESTRATÉGIAS DE LEGITIMIDADE DE SUCHMAN EVIDENCIADAS PELAS EMPRESAS BRASILEIRAS DESTINATÁRIAS DO PEDIDO DO CARBON DISCLOSURE PROJECT
} SUCHMAN'S LEGITIMACY STRATEGIES EVIDENCED BY
BRAZILIAN COMPANIES ADDRESSING THE APPLLYING
FOR OF CARBON DISCLOSURE PROJECT

Data de submissão: 23/01/2014 Aceite: $20 / 05 / 2016$

Luana das Graças Queiroz de Farias ${ }^{1}$ José Célio Silveira Andrade 2 Sônia Maria Silva Gomes ${ }^{3}$

\section{RESUMO}

Este artigo é fruto de uma tese de doutorado, oriunda de uma pesquisa exploratória realizada com dez casos empíricos. O Carbon Disclosure Project/Investidores no Brasil foi objeto de estudo dessa pesquisa. Criado em 2000, esse programa vem desempenhando um papel importante na evidenciação socioambiental, visando aumentar a transparência em torno dos riscos e das oportunidades relacionados à mudança climática. O estudo identificou as tipologias de estratégias de legitimidade de Suchman (1995) mais evidenciadas pelas empresas brasileiras destinatárias do pedido do Carbon Disclosure Project (CDP) no período de 2006 a 2010. Adotou-se a abordagem qualitativa e a técnica de análise de conteúdo para análise dos dados. Os dados primários foram coletados por meio de questionário, e os secundários foram obtidos nos sites institucionais, relatórios do CDP e do registro público de emissões da Fundação Getulio Vargas. Constatou-se a presença das estratégias de legitimidade propostas por Suchman. A legitimidade pragmática e o critério ganho obtiveram o maior número de citações, respectivamente 377 e 495 . 0 item mais citado em todos os dez estudos de caso foi responder às necessidades dos stakeholders, com 335 sentenças. Desse modo, pôde-se inferir que o CDP vem sendo considerado pelas empresas brasileiras como um mecanismo para obter aceitação e legitimidade perante as suas partes interessadas.

Palavras-chave: Carbon Disclosure Project-Brasil; Mudanças climáticas; Evidenciação; Estratégias de legitimidade de Suchman.

\footnotetext{
1 Possui graduação em Administração pela Universidade Estadual de Santa Cruz, UESC, mestrado em Planejamento Ambiental pela Universidade Estadual de Santa Cruz, UESC, e doutorado em Administração pela Universidade Federal da Bahia, UFBA. Salvador, Brasil. E-mail: luanafffarias@yahoo.com.br 2 Possui graduação em Engenharia Química pela Universidade Federal da Bahia, UFBA, mestrado em Engenharia Química pela Universidade Federal da Bahia, UFBA, e doutorado em Administração pela Universidade Federal da Bahia, UFBA. Atualmente é Professor Associado IV da Escola de Administração da Universidade Federal da Bahia. Salvador, Brasil. E-mail: celio.andrade@superig.com.br

3 Possui graduação em Ciências Contábeis pela Universidade Federal da Bahia, UFBA, mestrado em Controladoria e Contabilidade pela Universidade de São Paulo, USP e doutorado em Engenharia de Produção pela Universidade Federal de Santa Catarina, UFSC. Atualmente é professora Titular da Faculdade de Ciências Contábeis/UFBA, docente dos Programas de PósGraduação em Contabilidade (PPGCONT) e Administração (NPGA) da UFBA. Salvador, Brasil. E-mail: soniagomes3@gmail.com
} 


\section{ABSTRACT}

This article is the result of a doctoral dissertation based on exploratory research and 10 case studies. The Carbon Disclosure Project/Investors in Brazil is the empirical research object of this article. Since its creation in 2000, this program has been playing an important role, related to the disclosure of social and environmental information. It has aimed at improving the transparency upon climate change risks and opportunities. This study identified Suchman's legitimacy strategies (1995) that are most used by Brazilian companies, which have addressed the applied for Carbon Disclosure Project (CDP) between 2006 and 2010. Qualitative approach and content analysis technique were adopted in order to collect the data. The primary data were obtained through the application of a survey and the secondary data were obtained in institutional websites, CDP's reports and records on emissions collected by Fundação Getulio Vargas. All Suchman's legitimacy strategies were found in this study. The pragmatic strategy and the gain criteria obtained the biggest number of occurrences, 377 and 495 respectively. The most frequent cited item in all the 10 case studies was the necessity to respond to stakeholders, represented by 335 citations. Finally, it is possible to conclude that the CDP has been considered, by Brazilian companies, as a tool to obtain stakeholders' acceptance and legitimacy. strategies.

Keywords: Carbon Disclosure Project-Brazil; Climate change; Disclosure; Suchman legitimacy

\section{INTRODUÇÃO}

No século XX, a sociedade demonstrou uma crescente inquietude com a degradação da qualidade do ambiente natural. Essa preocupação, conhecida como consciência ecológica, manifestou-se, de forma individual, através de ajuste de conduta e, de forma coletiva, por meio da participação de Organizações Não Governamentais (ONGs), governos e empresas, visando à definição de práticas globais ambientalmente corretas.

A Conferência das Nações Unidas sobre Ambiente e Desenvolvimento (Cnumad), realizada há mais de vinte anos no Rio de Janeiro (Rio-92), instituiu que os países, os organismos internacionais e as empresas considerassem as questões ambientais na agenda internacional e nos diversos acordos multilaterais, não apenas como proteção ambiental, mas principalmente em demandas complexas de desenvolvimento sustentável, segurança energética e redução de emissões de Gases de Efeito Estufa (GEE), vinculando essas temáticas às propostas de desenvolvimento tanto internamente, na condução de processos e produtos, como no espaço externo, que envolve a comunidade e seu entorno.

A partir das negociações da Rio-92, as questões ambientais ganharam importância para as empresas, tanto na dimensão política como mercadológica. A relevância assumida pelo conceito de desenvolvimento sustentável e a emergência das questões climáticas no meio empresarial vêm consolidando uma nova forma de pensar e agir sobre as atividades econômicas e sociais, incluindo também os modelos gerenciais e conceituais das organizações, que informam e conduzem suas atividades.

Os efeitos da mudança climática têm sido um desafio à Governança Ambiental Global (GAG), ou seja, requerem um esforço coletivo entre governos, mercado e sociedade civil, no sentido de buscar alternativas possíveis à mitigação e/ou adaptação desse fenômeno. Até o momento, a maior parte das estratégias para diminuir esses efeitos está focada em instrumentos de mercado, operacionalizados no âmbito do mercado global de carbono (FARIAS et al., 2013).

A mudança climática representa um dos problemas ambientais mais desafiadores da contemporaneidade, e as ações ou inações de agora poderão afetar a própria vida no planeta (Viola; leis, 2001; GIDDENS, 2010). Entre as iniciativas assumidas pelas empresas para reduzir as emissões de GEE, o ge- 
renciamento dos riscos climáticos (físicos, mercadológicos, regulatórios e reputacionais) é uma das mais significativas, visto que pode impactar na dinâmica competitiva e na legitimidade das instituições.

Associado a essa temática, está o aumento do nível de conscientização do empresariado sobre a necessidade de tratar os problemas ambientais como fatores de legitimidade e de desempenho econômico na perseguição de metas e objetivos organizacionais. A teoria da legitimidade ajuda a explicar a adoção de certas práticas de evidenciação de caráter voluntário assumidas pelas organizações. Segundo essa teoria, ao adotar certas práticas sociais e ambientais, as empresas não necessariamente estariam pensando no bem-estar da sociedade, mas estariam tentando evitar sanções futuras, tais como: multas, regulação, pressões sociais, indenizações, reparação de danos, entre outros. Dessa forma, existiria um contrato implícito ou explícito entre elas e a sociedade (incluindo governo, funcionários, fornecedores, consumidores etc.) e, para buscar a legitimidade, as empresas precisariam seguir as regras desse contrato (DEEGAN; RANKIN; VOGHT, 2000; PATTEN, 1992).

Assim, determinadas práticas podem contribuir para aumentar ou diminuir o grau de legitimidade, afetando a capacidade de angariar recursos para sua sobrevivência. Esse fenômeno depende do sistema de crenças e valores vigentes no ambiente em que a organização está inserida (SUCHMAN, 1995). Para conquistar a legitimidade, muitas empresas têm adotado práticas de evidenciação ambiental, visto que a "elevação na quantidade de disclosure socioambiental reflete a preocupação delas serem percebidas como entidades responsáveis perante a sociedade e o ambiente onde desenvolvem suas atividades" (SAMPAIO et al., 2012, p. 1). A evidenciação ou disclosure ambiental é entendida como o conjunto de meios utilizados pelas organizações para informar seus stakeholders sobre como estão atuando em relação ao meio ambiente e à sociedade (Cormier; Gordon; Magnan, 2004; Ribeiro; Souza, 2004; ROSA; COSER, 2004).

Desse modo, como vem se consolidando no Brasil a utilização de uma prática internacional de carbon disclosure e ainda existem poucos estudos sobre esse fenômeno, esta investigação buscar responder: quais são as tipologias de estratégias de legitimidade de Suchman (1995) mais evidenciadas pelas empresas brasileiras signatárias do pedido do Carbon Disclosure Project (CDP) no período de 2006 a 2010? A pesquisa identificou as tipologias de estratégias de legitimidade de Suchman (1995) mais evidenciadas pelas empresas brasileiras destinatárias do pedido do CDP no período de 2006 a 2010, demonstradas nos questionários aplicados às dez empresas (dados primários).

O CDP é uma das iniciativas desenvolvidas pelo setor privado para responder ao problema ambiental global das mudanças climáticas - cujo objetivo é facilitar o diálogo entre investidores e corporações, através do disclosure (abertura) de informações relativas às estratégias corporativas para enfrentar as mudanças climáticas. Criado em 2005 no Brasil, o CDP/Investidores é um programa que objetiva analisar a tendência dos riscos e das oportunidades decorrentes das mudanças climáticas, atuando na criação de um banco global de dados sobre as emissões de carbono e subsidiando os investidores e gestores de informações climáticas no processo de tomada de decisão. Trata-se de um requerimento coletivo enviado por investidores institucionais às empresas listadas nas principais bolsas de valores do mundo, com o intuito de constituir um banco de dados sobre as políticas climáticas adotadas pelos diferentes setores produtivos.

Esta pesquisa traz contribuições práticas, pois ajudará as organizações a se autorreconhecerem no que diz respeito às suas ações visando à legitimidade e auxiliará também os investidores a identificarem sobre quais bases as empresas tomam decisões, qual o interesse por detrás de suas ações, o que as deixará mais conscientes nas decisões de investimento. Ademais, este estudo inova na medida em que busca investigar o quanto as informações disponibilizadas pelo Carbon Disclosure Project/Investidores estão alinhadas com as tipologias propostas por Suchman 
(1995), enquanto as investigações realizadas sob o aparato conceitual das estratégias de legitimidade da tipologia de Suchman (1995) costumam trabalhar com Relatórios de Administração (BEUREN, 2009; FANK; BEUREN, 2010; MAHADEO; OOGARAH-HANUMAN; SOOBAROYEN, 2011).

Este artigo está subdividido em quatro partes, além desta introdução: na primeira parte, são apresentadas uma revisão teórica sobre legitimidade organizacional e as tipologias de legitimidade organizacional de Suchman (1995); na segunda, são expostos os procedimentos metodológicos utilizados na pesquisa; na terceira seção, destaca-se a discussão dos resultados; e a última seção aborda as considerações e recomendações finais do estudo.

\section{LEGITIMIDADE ORGANIZACIONAL}

Na concepção de Suchman (1995, p. 574, tradução nossa), a legitimidade é definida como "a percepção ou premissa generalizada de que as ações de uma organização são desejáveis ou apropriadas dentro de algum sistema socialmente construído de normas, valores, crenças e definições". Além disso, o autor destaca que, a depender do sistema de crenças e valores vigentes no ambiente em que organizações atuam, determinadas práticas podem contribuir para aumentar ou diminuir o grau de legitimidade, afetando a capacidade de angariar recursos para sua manutenção. Esse conceito pode ser reconhecido como um fenômeno macrossocial que busca fornecer às organizações, além de recursos técnicos e informacionais, aceitação e credibilidade necessária para sua sobrevivência (MEYER; ROWAN, 1977; SUCHMAN, 1995).

No âmbito organizacional, uma das primeiras concepções de legitimidade foi desenvolvida por Parsons, na década de 1950. Segundo essa concepção, a legitimidade era entendida "como avaliação da ação em termos de valores comuns ou compartilhados no contexto do envolvimento da ação no sistema social" (Dowling; Pfeffer, 1975, p. 123). Posteriormente, ela foi revisitada por Dowling e Pfeffer (1975, p. 122) e direcionada às organizações por meio "da congruência entre os valores sociais associados ou implicados pelas atividades organizacionais e as normas de comportamento aceitável no ambiente social maior". Desse modo, a legitimidade organizacional é um processo social, proveniente da ação de indivíduos e das organizações e, por isso, constituído a partir de valores socialmente legítimos (Dowling; Pfeffer, 1975).

Outra origem difundida desse conceito está associada à noção de contrato social. Derivada da Teoria dos Contratos, o termo "legitimidade organizacional" é utilizado em pesquisas que buscam explicar e predizer práticas de evidenciação de caráter social e ambiental, no ambiente corporativo (O'Donovan, 2000; DIAS FILHO, 2008).

Mas, apesar das diferentes abordagens desse conceito, seu desenvolvimento adquiriu notoriedade com os trabalhos de Lindblom (1994) e Suchman (1995), na década de 1990 (Gray; KOUHY; LAVERS, 1995). Lindblom (1994) propôs em seu artigo "The implications of organizational legitimacy for corporate social performance and disclosure" uma definição frequentemente mencionada na área de Contabilidade Social e Ambiental.

Para o Lindblom (1994, p. 2), legitimidade organizacional significa "[...] a condição ou o estado que existe quando o sistema de valores de uma entidade é congruente com o sistema de valores do amplo sistema social do qual a entidade faz parte". Suchman (1995), entretanto, foi o autor que idealizou a definição mais utilizada sobre legitimidade organizacional, em âmbito nacional e internacional (ROSSONI; TEIXEIRA, 2008; ROSSONI, 2012). Nessa perspectiva, Suchman (1995, p. 574) amplia o conceito de legitimidade organizacional, inserindo outras fontes além da cultural e propondo uma tipologia de estratégias de legitimidade composta por três categorias legitimidade pragmática, moral e cognitiva. 


\subsection{Tipologias de legitimidade organizacional segundo Suchman (1995)}

Os estudos de legitimidade organizacional de Suchman (1995) consideram dois grupos distintos: o estratégico e o institucional. A abordagem estratégica enfatiza as organizações instrumentais e suas ações para persuadir, manipular e implantar símbolos que visem obter o apoio da sociedade. Já a institucional busca formas pelas quais as "estruturas setoriais geram pressões culturais que transcendem a qualquer controle intencional da organização" (MACHADO, 2014, p. 20).

As propostas de estratégias de legitimação apresentadas por Suchman (1995) representam uma síntese de suas investigações a respeito do assunto, cujos resultados culminaram em uma tipologia dividida em três categorias, denominadas pragmática, moral e cognitiva. Essa tipologia parte do pressuposto de que as atividades organizacionais são desejáveis, de acordo com um conjunto socialmente adequado composto por normas, valores, crenças e definições. Cada tipo ocorre sob diferentes dinâmicas e formas de comportamento, as quais serão explicadas a seguir.

a. Legitimidade pragmática

A legitimidade pragmática fundamenta-se no imediatismo da empresa com relação às respostas sobre a percepção do seu público-alvo. Esse imediatismo na troca entre organização e público também envolve as relações institucionais (política, econômica e social) da entidade, em que cada ação organizacional impacta a percepção do público. Para Machado (2014), esse imediatismo muitas vezes envolve intercâmbio direto entre a organização e seu público, resultando em respostas às percepções de seu público particular. Outra forma utilizada para estabelecer a legitimidade pragmática está relacionada ao termo "influência". Neste caso, a organização conta com o apoio da sociedade, mas não porque a sociedade acredite que o intercâmbio traga benefícios diretos, e sim porque percebe que a organização está sensível aos seus maiores interesses.

Muitas vezes, esta concepção de rapidez que abarca a organização e seu público-alvo também passa a envolver, de forma ampla, suas relações institucionais nos aspectos políticos, econômicos e sociais da entidade, em que cada ação praticada afeta diretamente essa percepção (SUCHMAN, 1995). Thomas e Lamn (2012) esclarecem que a legitimidade pragmática reflete a avaliação de um indivíduo sobre as ações organizacionais em gerar benefícios tangíveis para a própria organização e seus stakeholders.

\section{b. Legitimidade moral}

Ela baseia-se numa avaliação do comportamento ético da organização. Reflete uma avaliação de crenças normativas da organização e de suas atividades. Essa tipologia de legitimidade "sociotrópica" é pautada em juízos e valores sobre se a atividade é a "coisa certa a se fazer" (SUCHMAN, 1995). Os julgamentos normalmente refletem as crenças e o sistema de valores socialmente construídos.

Essa avaliação almeja compreender se a atividade da organização efetivamente promove o bem-estar da sociedade, tal como definido pelo sistema de valores socialmente construídos As organizações habitualmente reivindicam sua legitimidade moral por simbologias, códigos e normas de conduta que muitas vezes ficam assinaladas na percepção da sociedade como um todo.

\section{c. Legitimidade cognitiva}

Compreende o apoio afirmativo para uma organização ou uma simples aceitação da organização como necessária ou inevitável. Nesse sentido, pode-se afirmar que a legitimidade cognitiva é mediada entre os quadros de referências de empresas e concorrentes em um deter- 
minado contexto sociopolítico. Reforça Suchman (1995) que, no nível cognitivo, os esforços de legitimação são os mais bem dirigidos a explicar a linha de negócios como sendo simples e natural, estimulando a compreensão dos esforços da empresa para seus funcionários e para o mundo exterior. Uma estratégia descrita para a obtenção de legitimidade cognitiva se dá pelo apoio ou reconhecimento de estruturas formais externas para suas atividades. $\mathrm{O}$ autor, todavia, salienta o papel dos discursos normativos na formação cognitiva da legitimação. As organizações precisam entender como os discursos morais estão mudando e como influenciam a participação ativa das ações normativas das empresas. Organizações tendem a aplicar esse discurso em um nível coletivo, tais como a criação do Conselho para o Desenvolvimento Sustentável.

Segundo Dias Filho (2008), os contratos ou estruturas normativas são construídos em função do sistema de crenças e valores vigente. Assim, a partir do momento em que a sociedade prioriza questões sociais e ambientais, em tese, qualquer ação que descuide desses aspectos tende a ser desaprovada pela própria sociedade. Essas situações podem ocorrer mediante um rompimento do suposto contrato e isso, no cotidiano da organização, pode provocar dificuldades para a continuidade dos negócios, em função de possíveis sanções sociais, como resistência de fornecedores e consumidores, denúncias nos meios de comunicação, entre outras (MACHADO, 2014).

As instituições não visualizam apenas os prováveis transtornos, mas elas transformam em atividades determinadas ações que impossibilitam qualquer desavença. Nessa tipologia, a tomada de decisão para as organizações que atingem sua aceitação pode ser implementada através de programas, normas, regulamentos e estatutos (SUCHMAN, 1995).

Suchman (1995) estabeleceu, para as três categorias de legitimidade, critérios e itens a serem analisados na gestão de sua legitimidade social. $\mathrm{O}$ autor indica que as empresas podem realizar ações com o objetivo de ganhar, manter e recuperar a legitimidade. Para tanto, a organização pode agir de forma pragmática, moral e cognitiva, usando diferentes formas de legitimidade.

Por exemplo, Suchman (1995) admite que a gestão da legitimidade está pautada na comunicação entre a organização e seus diferentes públicos. Normalmente, a organização empreende muitas ações para ser aceita no seu contexto social quando implementa novas operações técnicas, possui problemas ou está mal institucionalizada.

Buscando alcançar legitimidade pragmática através da conformidade, a organização deve satisfazer as necessidades de diversos públicos ou oferecer acesso à tomada de decisão. Alguns passos são sugeridos, como responder às preferências dos clientes e ampliar a cooptação de novos.

Outra proposta descrita é a seleção de ambientes. Essa opção deve ocorrer naturalmente através de pesquisa de mercado, almejando identificar e atrair novos clientes que se identifiquem com os tipos de troca que a organização está apta a fazer.

Na dimensão cognitiva, os gestores podem realizar seleções de ambiente por meio de manipulação estratégica das declarações de metas/objetivos. Em ambientes muito institucionalizados, há entidades formais de rotulagem que limitam o acesso às informações privilegiadas.

Os itens foram desenvolvidos para servir de parâmetro na identificação dos tipos de legitimidade nos relatórios publicados pelas empresas e, portanto, para verificar se as organizações estão buscando, por meio de suas ações e evidenciação, a legitimidade perante a sociedade, cujas estratégias estão evidenciadas no Quadro 1. 
Quadro 1 - Estratégias de Legitimidade Organizacional

\begin{tabular}{|c|c|c|c|}
\hline \multirow[t]{2}{*}{ CATEGORIAS } & \multicolumn{3}{|c|}{$\begin{array}{c}\text { Estratégias para a legitimação } \\
\text { CRITÉRIOS }\end{array}$} \\
\hline & GANHO & MANUTENÇÃO & REPARAÇÃO \\
\hline \multirow{6}{*}{ PRAGMÁTICA } & ITENS & ITENS & ITENS \\
\hline & $\begin{array}{l}\text { Responder às necessidades dos } \\
\text { stakeholders }\end{array}$ & Consultar a opinião de líderes & Rejeitar \\
\hline & Cooptar integrantes & Monitorar a confiabilidade & Criar monitores \\
\hline & Construir reputação & Comunicar-se honestamente & \\
\hline & Anunciar o produto & Estocar confiança & \\
\hline & Anunciar a imagem & & \\
\hline \multirow{6}{*}{ MORAL } & Produzir resultados adequados & $\begin{array}{c}\text { Consultar as categorias profis- } \\
\text { sionais }\end{array}$ & $\begin{array}{l}\text { Desculpar/justi- } \\
\text { ficar }\end{array}$ \\
\hline & Incorporar-se a instituições & Monitorar a responsabilidade & Substituir pessoa \\
\hline & Oferecer demonstrações simbólicas & Comunicar-se oficialmente & Rever as práticas \\
\hline & Definir metas & \multirow{3}{*}{ Estocar opiniões favoráveis } & \multirow{3}{*}{ Reconfigurar } \\
\hline & Demonstrar sucesso & & \\
\hline & $\begin{array}{l}\text { Fazer proselitismo (indivíduo con- } \\
\text { vertido a uma doutrina ou ideia) }\end{array}$ & & \\
\hline \multirow{7}{*}{ COGNITIVA } & Reproduzir normas & $\begin{array}{l}\text { Consultar aquele que tem dú- } \\
\text { vidas }\end{array}$ & Explicar \\
\hline & Formalizar as operações & Visar clareza & \\
\hline & Profissionalizar as operações & Falar pontualmente & \\
\hline & Buscar certificações & Estocar conexões & \\
\hline & Persistir & & \\
\hline & Popularizar novos modelos & & \\
\hline & Padronizar novos modelos & & \\
\hline
\end{tabular}

Fonte: adaptado de Suchman (1995).

As tipologias de legitimidade não constituem uma hierarquia, mas refletem duas distinções importantes entre si. Primeiro, a legitimidade pragmática depende do interesse próprio da audiência, enquanto a legitimidade moral e a cognitiva envolvem regras culturais mais abrangentes.

\section{PROCEDIMENTOS METODOLÓGICOS}

Esta pesquisa caracteriza-se como um estudo exploratório com uso de abordagem qualitativa dos dados, realizada por meio de dez casos empíricos. Os dados primários foram obtidos através da aplicação dos questionários, e os secundários, retirados dos relatórios institucionais das empresas, do Carbon Disclosure Project e do registro público de emissões da Fundação Getúlio Vargas. Para a análise dos dados primários, foi utilizada a técnica de análise de conteúdo sugerida por Bardin (2009). Após a análise de conteúdo, os dados coletados foram quantificados e organizados à luz do framework de Suchman (1995), conforme o Quadro 1.

Quanto ao objeto da pesquisa, este foi composto pelas oitenta empresas brasileiras destinatárias do pedido de disclosure do Carbon Disclosure Project/Investidores que responderam pelo menos uma vez ao questionário do CDP no período de 2006 a 2010 . O questionário foi organizado pelos autores, contendo questões de alternativas múltiplas, tendo questões abertas e fechadas, possibilitando alcançar os objetivos da pesquisa. Realizou-se pré-teste, e o meio escolhido para distribuição do questionário foi o correio eletrônico. 
Para selecionar a amostra referente aos casos empíricos, foi enviado através do correio eletrônico um questionário solicitando informações para todas as oitenta empresas classificadas por setor produtivo, visando à realização de estudo de caso empírico para cada um dos 12 setores que compõem o universo das oitenta empresas. Assim, foi escolhida uma empresa de cada setor que tivesse respondido ao questionário no período de novembro de 2011 a novembro de 2012, para compor a amostra desta pesquisa, determinando aqui a escolha dos estudos de casos empíricos pelos critérios da acessibilidade e conveniência. Como nenhuma empresa pertencente aos setores de Mineração e Telecomunicações respondeu ao questionário, a amostra desta pesquisa foi composta por dez casos empíricos dos setores apresentados no Quadro 2.

Quadro 2 - Distribuição dos casos empíricos por setor produtivo da amostra

\begin{tabular}{|c|c|c|}
\hline CASO & SETOR & empresa objeto do estudo de caso \\
\hline 1 & Petróleo e Gás e Biocombustíveis & Petróleo Brasileira S.A. (Petrobras) \\
\hline 2 & Metalurgia e Siderurgia & Arcelor Mittal Brasil S.A \\
\hline 3 & Utilidade Pública & Cia Energética de São Paulo (CESP) \\
\hline 4 & Indústria de Alimentos & Braskem \\
\hline 5 & Petroquímicos & Banco do Brasil \\
\hline 6 & Financeiro & Fibria \\
\hline 7 & Papel e Celulose & América Latina Logística S.A. \\
\hline 8 & Construção e Transporte & Microinox \\
\hline 9 & Indústria de bens/equipamentos & Odonto Prev \\
\hline 10 & Consumo e Serviços & Não respondeu ao questionário \\
\hline 11 & Telecomunicações & Não respondeu ao questionário \\
\hline 12 & Mineração & \\
\hline
\end{tabular}

Fonte: dados da pesquisa.

\section{RESULTADOS DA PESQUISA}

Nesta seção, são apresentadas algumas considerações a respeito das estratégias de enfrentamento das mudanças climáticas e das estratégias de legitimidade de Suchman (1995) mais evidenciadas nos dez casos empíricos. Os dados primários do questionário foram complementados pelas informações publicadas nos sites - das próprias empresas e extraídos dos relatórios do Carbon Disclosure Project e do registro público de emissões da Fundação Getúlio Vargas.

O resultado da pesquisa demonstrou que o tema das mudanças climáticas está sendo introduzido na agenda corporativa dos setores investigados, principalmente pela necessidade de as organizações compreenderem o impacto de suas atividades no ambiente e buscarem aceitação de suas ações perante seus stakeholders.

Para efeito de comparação entre os setores, observou-se que a maioria deles declarou possuir emissões diretas no escopo 1 e indiretas nos escopos 2 e 3. 0 escopo 1 representa as emissões diretas (em geral, incluem emissões originadas pelos processos produtivos na empresa); o escopo 2 representa as emissões indiretas (equivalem às energias compradas de terceiros e ocorrem nas plantas produtivas das empresas); e o escopo 3, outras emissões indiretas de fontes não controladas (envolvem outras emissões que são consequência das atividades da empresa, mas são oriundas de outras fontes, como, por exemplo, as emissões geradas pelo uso dos produtos da empresa, pelo transporte do material, por viagens a negócios, entre outros).

Esse resultado reflete ações ligadas à legitimidade pragmática, observando o interesse da organização sobre as respostas imediatas da percepção do seu público. Muitas vezes, essa 
concepção também envolve de forma ampla suas relações institucionais nos aspectos políticos, econômicos e sociais da entidade, em que cada ação praticada afeta diretamente essa percepção (SUCHMAN, 1995). Nesse sentido, a legitimidade pragmática tem como foco os efeitos sobre a troca da influência dos atos da entidade e seus diferentes stakeholders.

No entanto, apenas três empresas (Petrobras, JBS e Banco do Brasil) admitem a realização de inventário através da metodologia GHG Protocol. O GHG Protocol é um programa desenvolvido pela World Resources Institute (WRI) em parceria com o World Business Council for Sustainable Development (WBSCD) e adaptado ao contexto nacional para fornecer uma maneira de produzir inventário das emissões de carbono (GEE). Trata-se de realização de inventários de emissão de GEE, com metas e prazos definidos, visando ao aprimoramento contínuo das ações de redução de GEE. Entre os dez casos, apenas as empresas Banco do Brasil, América Latina Logística e Microinox evidenciaram não possuir programa de redução de GEE.

De acordo com Dias Filho (2007, p. 6), a legitimidade "baseia-se na ideia de que existe uma espécie de contrato social entre as organizações e a sociedade em que atuam, representando um conjunto de expectativas implícitas ou explícitas de seus membros a respeito da forma como elas devem operar". Na medida em que as organizações são aceitas, passam a trabalhar para manter essa legitimidade, realizando suas atividades normalmente e dentro dos padrões novos ou antigos estabelecidos; ou, então, passam a trabalhar para recuperar a legitimidade abalada ou perdida em vista de fatos ou eventos negligentes em relação às suas atividades.

Quanto aos riscos e às oportunidades, os casos demonstraram que o setor econômico em que a empresa está inserida influencia tanto na forma como as mudanças climáticas são percebidas quanto no emprego de esforços para aprimorar as competências organizacionais.

Os riscos estão sendo gerenciados pelos setores em função dos custos envolvidos no atendimento às exigências regulatórias e de eficiência energética. O risco mercadológico foi o mais frequente, sendo citado oito vezes, seguido pelo reputacional, presente em seis casos. Já o regulatório foi identificado como o mais importante risco climático. Ele está presente nos casos Petrobras, Arcelor, Banco do Brasil, Fibria e ALL, incluindo aqui setores críticos e de alta visibilidade, como Petróleo e Gás, Financeiro, Siderurgia, Transporte e Papel e Celulose.

Os riscos regulatórios, contudo, definem as regras do jogo no país, passando a ser um indutor significativo para todas as iniciativas de investimentos dos setores produtivos. Discussões a respeito do risco regulatório e do impacto sobre o risco e o retorno de empresas ganham destaque nas decisões de investimentos. $O$ risco regulatório pode ser percebido como um componente característico do risco de empresas sujeitas a regulação, decorrente de fatores como modificações na estrutura legal, atualizações tarifárias e tantas outras formas de obrigação de limites e restrições impostas pelos governos.

As organizações mudarão sua estrutura de operações para alinhá-la com as expectativas e valores dos seus stakeholders. Essa estrutura não se sustenta em decisões sobre uma determinada atividade, a qual traz benefício ao público-alvo, mas em atividades que possuem a característica de "se fazer a coisa certa" (SUCHMAN, 1995). Contudo, as decisões refletem crenças e as atividades promovem efetivamente o bem-estar da sociedade, tal como definido pelo sistema de valores socialmente construídos.

Por outro lado, as modificações criadas nos ambientes regulatórios e mercadológicos originam muitas oportunidades setoriais, tais como: desenvolvimento de produtos e atração de investidores - preferidos pelos setores, estando presentes em oito casos; participação em Mercado de Crédito de Carbono e antecipação e influência sobre as ações regulatórias nas mudanças climáticas, que foram citadas por quatro casos cada uma. Quando se analisa o potencial de indu- 
ção, vê-se uma valorização desse aspecto pelos casos Petrobras, CESP, Braskem e Banco do Brasil. Os principais fatores indutores observados foram: iniciativa voluntária visando à eficiência energética (10); prática de responsabilidade social corporativa (9); ganhos de reputação da empresa diante da pressão de investidores nacionais e internacionais (9); iniciativa voluntária visando à minimização dos efeitos das mudanças climáticas decorrentes do carbono (8), redução de custos e competitividade empresarial; (8) e oportunidade de novas fontes de financiamento e capital (8). A iniciativa voluntária visando à eficiência energética foi citada em todos os casos.

De forma geral, as ações de combate às mudanças climáticas são bem diversificas e estão alinhadas ao conceito de sustentabilidade corporativa ou de responsabilidade social da empresa. As iniciativas mostraram-se adequadas para a maioria dos casos, e as principais identificadas, com seis citações cada, foram: aperfeiçoamento de produto(s) e/ou serviços visando reduzir suas emissões de GEE; gerenciamento ambiental (ISO 14000 ou outro) e responsabilidade social (ISO 26000); transformação de resíduos dos processos produtivos em coprodutos; e ações voluntárias visando à quantificação e monitoramento de emissões próprias de GEE. Observou-se que, das 25 iniciativas apresentadas no questionário, 19 foram indicadas no caso 1 (Petrobras). Nos demais, a maior participação foi representada pelos casos CESP, Arcelor, Banco do Brasil e Fibria, com, respectivamente, 15, 14, 10 e 10 ações cada, envolvendo a redução de suas emissões. Ressalta-se que o caso 9 (Microinox) identificou apenas uma iniciativa, qual seja, utilização de processos produtivos de baixa emissão de GEE.

Nesse sentido, no desenvolvimento de suas atividades, as organizações buscam reparar e aumentar seu estado de legitimidade na sociedade, quando a manutenção desse status estiver ameaçada. Com base no exposto, Machado (2014, p. 35) afirma que a "organização pode adaptar a sua produção, objetivos e métodos de operação em conformidade com as definições vigentes de legitimidade, como, por exemplo, alterar o processo produtivo de forma a reduzir a emissão de GEE".

Em relação à criação de uma ambiência organizacional envolvendo o clima, a cultura e o comprometimento que facilite a execução das estratégias climáticas - conjunto de metas e planos de uma corporação visando à redução das emissões de GEE, produzindo benefícios associados de relevância e/ou objetivando responder às demandas e alterações decorrentes das mudanças climáticas nos âmbitos de mercado, política pública ou ambiente físico -, os casos revelaram aspectos bem diversificados. Os itens participação direta dos empregados e participação direta da alta administração na implantação de atividades ligadas às questões climáticas foram mencionados por todos os casos (10) e seguidos pela divulgação externa das estratégias relativas às mudanças climáticas às partes interessadas (investidores, governo, sociedade etc.) e pelo programa de conscientização dos empregados referente às mudanças climáticas, ambos com nove citações. Em contrapartida, o bônus financeiro associado ao alcance de metas climáticas foi o menos citado, presente em apenas quatro casos: Petrobras, CESP, Banco do Brasil e ALL. Ainda, quanto ao clima de motivação, os obstáculos considerados importantes pelos setores foram a carência de competências organizacionais necessárias ao trato de questões relativas às mudanças climáticas e a existência, na empresa, de fontes de resistência a assuntos ligados às mudanças climáticas, com sete menções, seguidos por riscos mercadológicos e reputacionais, com cinco citações. No entanto, o caso 6 (Banco do Brasil) relatou o maior número de obstáculos (7).

Observou-se também, nos casos estudados, que as parcerias com os stakeholders são fundamentais para o êxito das ações internas desenvolvidas pelas empresas. Aqui, as parcerias com ONGs foram o principal mecanismo de cooperação, com a presença em oito casos. Em seguida, foram citadas a participação em reunião para negociação de acordos, fóruns, conferências, workshops e outros e a obtenção de assentos nas câmaras, comitês e demais instituições empre- 
sariais e governamentais para influenciar as regras do jogo sobre a regulamentação do problema das mudanças climáticas nos níveis local, nacional e global, com, respectivamente, sete e seis menções. Essa teoria visa explicar a razão de determinados comportamentos organizacionais e, por essa razão, é muito útil quando se trata de buscar compreender o comportamento das empresas frente às demandas socioambientais.

Machado (2014), por exemplo, enfatiza que a participação das empresas e das partes interessadas está mais baseada em avaliações normativas de decoro moral, legitimidade baseada em definições cognitivas, do que necessariamente no entendimento de atividades adequadas.

Para Suchman (1995), as organizações tendem a conciliar (de fato ou na aparência) os seus sistemas com esse sistema social por meio do processo de legitimação.

Esse contrato, segundo Dias Filho (2008), é construído em função do sistema de crenças e valores vigente. Assim, a partir do momento em que a sociedade valoriza questões sociais e ambientais, em tese, qualquer atividade que negligencie esses aspectos tende a ser reprovada pela própria sociedade. Em tais circunstâncias, ocorre um rompimento do suposto contrato e isso, na prática, pode atrair dificuldades para a continuidade de uma organização, em função de possíveis sanções sociais, como resistência de consumidores e fornecedores, denúncias nos meios de comunicação, multas etc.

Entre os casos empíricos, apenas a Petrobras e a Braskem apresentaram maior número de interações com os parceiros externos, com, respectivamente, sete e oito mecanismos de interação cada. Acredita-se que, em função da exposição dos setores Petróleo e Gás e Petroquímica, a alta regulamentação e o desenvolvimento de estratégias políticas bem definidas faz com que esses setores utilizem diferentes meios de Governança Ambiental Global (GAG), para legitimar suas ações junto à sociedade, principalmente investidores e governo.

No que se refere aos meios utilizados pelos setores para publicarem informações sobre suas ações de redução das emissões de GEE, constatou-se que eles são amplos e podem elevar a credibilidade e a transparência das empresas. Entre eles, o site institucional é o principal meio, estando presente em nove casos. Já os casos 6 (Banco do Brasil) e 9 (Microinox) demonstram situações diferentes. Enquanto o Banco do Brasil publica em todos os meios de divulgação e inclui também o programa brasileiro GHG Protocol/ICO2 BNDES e BMF\&BOVESPA, a Microinox informou que não publica informações em nenhum outro meio de disclosure voluntário, exceto o CDP. Ainda abordando essa questão, sete casos reconheceram que as práticas de disclosure ambiental são realizadas pelas empresas com o objetivo de divulgar informações para todas as partes interessadas, visto que são os constituintes do ambiente externo que podem conceder legitimidade e colaborar para a sobrevivência da organização.

Quanto às estratégias de legitimidade de Suchman (1995), o Quadro 3, a seguir, agrupou as 665 sentenças referentes às três estratégias de legitimação identificadas nos questionários aplicados às empresas signatárias do pedido do CDP/Investidores. 
Quadro 3 - Estratégias de legitimação - tipologias mais evidenciadas

\begin{tabular}{|c|c|c|c|c|c|c|c|c|c|c|c|c|}
\hline \multicolumn{12}{|c|}{ ESTRATÉGIAS DE LEGITIMAÇÃO - RESUMO DAS ESTRATÉGIAS } & \multirow{3}{*}{$\begin{array}{l}\text { TO- } \\
\text { TAL }\end{array}$} \\
\hline \multirow{2}{*}{$\begin{array}{l}\text { CATE- } \\
\text { GORIAS }\end{array}$} & \multirow{2}{*}{$\begin{array}{l}\text { CRITÉ- } \\
\text { RIOS }\end{array}$} & \multicolumn{10}{|c|}{ CASOS } & \\
\hline & & $\begin{array}{c}\text { Caso } 1 \\
\text { Petro- } \\
\text { bras }\end{array}$ & $\begin{array}{c}\text { Caso } 2 \\
\text { Arcelor }\end{array}$ & $\begin{array}{c}\text { Caso } \\
3 \\
\text { CESP }\end{array}$ & $\begin{array}{c}\text { Caso } \\
4 \\
\text { JBS }\end{array}$ & $\begin{array}{c}\text { Caso } 5 \\
\text { Braskem }\end{array}$ & $\begin{array}{c}\text { Caso } 6 \\
\text { Banco } \\
\text { do } \\
\text { Brasil }\end{array}$ & $\begin{array}{c}\text { Caso } 7 \\
\text { Fibria }\end{array}$ & $\begin{array}{c}\text { Caso } \\
8 \\
\text { ALL }\end{array}$ & $\begin{array}{c}\text { Caso } 9 \\
\text { Microi- } \\
\text { nox }\end{array}$ & $\begin{array}{c}\text { Caso } \\
10 \\
\text { Odonto } \\
\text { Prev } \\
\end{array}$ & \\
\hline $\begin{array}{l}\text { PRAG- } \\
\text { MÁTICA }\end{array}$ & Ganho & 50 & 42 & 35 & 45 & 38 & 43 & 36 & 32 & 17 & 25 & 363 \\
\hline MORAL & Ganho & 14 & 6 & 5 & 3 & 6 & 7 & 10 & 2 & 1 & 4 & 58 \\
\hline $\begin{array}{l}\text { COGNI- } \\
\text { TIVA }\end{array}$ & Ganho & 14 & 5 & 5 & 6 & 14 & 8 & 9 & 7 & 0 & 6 & 74 \\
\hline $\begin{array}{l}\text { PRAG- } \\
\text { MÁTICA }\end{array}$ & $\begin{array}{c}\text { Manu- } \\
\text { ten- } \\
\text { ção } \\
\end{array}$ & 2 & 2 & - & 6 & - & 1 & 1 & 1 & - & 1 & 14 \\
\hline MORAL & $\begin{array}{c}\text { Manu- } \\
\text { ten- } \\
\text { ção } \\
\end{array}$ & 10 & 9 & 6 & 12 & 10 & 5 & 4 & 11 & 1 & 8 & 76 \\
\hline $\begin{array}{l}\text { COGNI- } \\
\text { TIVA }\end{array}$ & $\begin{array}{c}\text { Manu- } \\
\text { ten- } \\
\text { ção } \\
\end{array}$ & 1 & - & - & 1 & - & - & - & - & - & - & 2 \\
\hline $\begin{array}{l}\text { PRAG- } \\
\text { MÁTICA }\end{array}$ & $\begin{array}{l}\text { Repa- } \\
\text { ração }\end{array}$ & - & - & - & - & - & - & - & - & - & - & - \\
\hline MORAL & $\begin{array}{l}\text { Repa- } \\
\text { ração }\end{array}$ & 7 & 7 & 10 & 5 & 8 & 4 & 7 & 12 & 10 & 5 & 75 \\
\hline \multirow[t]{2}{*}{$\begin{array}{l}\text { COGNI- } \\
\text { TIVA }\end{array}$} & $\begin{array}{l}\text { Repa- } \\
\text { ração }\end{array}$ & - & 1 & 1 & 1 & - & - & - & - & - & - & 3 \\
\hline & Total & 98 & 72 & 62 & 79 & 76 & 68 & 67 & 65 & 29 & 49 & 665 \\
\hline
\end{tabular}

Fonte: dados da pesquisa.

As estratégias de legitimidade estão subdivididas em três critérios: ganho, manutenção e reparação. Referente ao critério ganho de legitimidade, obtiveram-se 495 evidenciações nos questionários; em seguida, aparece a manutenção, com 92 evidenciações, e, por último, a reparação, com 74 evidenciações. Quanto ao ganho de legitimidade, em primeiro lugar, ficou a estratégia pragmática, com 377 evidenciações; em seguida, a estratégia cognitiva, com 74; e, por último, a estratégia moral, com 58 citações. Nos critérios manutenção e reparação, destaca-se a estratégia moral, com 76 e 75 evidenciações, respectivamente.

Em relação ao framework de Suchman (1995), predominaram a estratégia pragmática e o item responder às necessidades em todos os casos analisados, totalizando 377 e 335 evidenciações, respectivamente. As ações desenvolvidas pela estratégia pragmática visam melhorar a imagem e a percepção imediata que a sociedade tem sobre as organizações, sobretudo aquelas que integram setores intensivos em uso de recursos naturais e de alta visibilidade.

Conforme Suchman (1995), a legitimidade pragmática está centrada no interesse da organização sobre as respostas imediatas da percepção do seu público. Essa compreensão, além de abarcar a organização e seu público-alvo, também abrange a diversidade de suas relações institucionais nos aspectos políticos, econômicos e sociais, em que cada ação cometida afeta diretamente essa percepção (SUCHMAN, 1995). Além disso, na estratégia pragmática, as empresas do CDP/Investidores preocupam-se em proteger sua imagem e em construir sua reputação através da utilização do disclosure voluntário como relatório anual de sustentabilidade e comunicações voluntárias de responsabilidade social empresarial em revistas especializadas, buscando, logo, ganhar legitimidade. 
$\mathrm{Na}$ categoria legitimidade moral, observou-se que, nos casos analisados, predominou o critério manutenção, com 76 citações. Os itens preocupação em rever as práticas, monitorar a responsabilidade, incorporar às instituições e comunicar oficialmente foram os mais evidenciados. Em geral, a legitimidade moral reflete uma avaliação positiva ou normativa da organização e das suas atividades.

Analisando-se os resultados relativos à categoria de legitimidade cognitiva, verificou-se que o critério ganho obteve 74 evidenciações e os itens mais citados foram formalizar as operações, profissionalizar as operações, popularizar modelos e buscar certificação perante órgãos reguladores. Isso demonstra a preocupação das empresas em reproduzir normas, formalizar e profissionalizar as operações e buscar certificação perante órgãos reguladores, demonstrando a forma correta pela qual as empresas desenvolvem suas atividades e, consequentemente, diminuem a possibilidade de ocorrerem falhas no processo. A legitimidade cognitiva está pautada em preceitos culturais e na aceitação do papel das organizações pela sociedade.

As empresas que apresentaram o maior número de evidenciações das estratégias de legitimidade de Suchman (1995) foram Petrobras (caso 1), JBS (caso 4), Braskem (caso 5) e Arcelor (caso 2), com, respectivamente, 98, 79, 76 e 72 evidenciações cada.

Entre os casos, o primeiro apresentou maior número de evidenciações na estratégia pragmática e no critério ganho, com 50 e 78 evidenciações, simultaneamente. A predominância da estratégia pragmática, todavia, pode estar associada ao fato de que as companhias petrolíferas possuem um custo político e social elevado e aumentam a sua preocupação e atenção com o tema.

\section{CONSIDERAÇÕES E RECOMENDAÇÕES FINAIS}

Como se afirmou neste trabalho, a questão da mudança climática constitui sério desafio para as políticas ambientais contemporâneas governamentais e empresariais. Cada vez mais, os efeitos dessas mudanças estão afetando as organizações, exigindo novos modelos gerenciais, políticas e ações que legitimem suas atividades perante a sociedade.

O estudo objetivou identificar as tipologias de estratégias de legitimidade de Suchman (1995) mais evidenciadas pelas empresas brasileiras destinatárias do pedido do Carbon Disclosure Project no período de 2006 a 2010. Para atingir o objetivo proposto, foi realizada pesquisa exploratória, com abordagem qualitativa dos dados. Na análise dos dados, foi utilizada a técnica de análise de conteúdo das evidenciações contidas nos questionários respondidos pelas empresas que compuseram os estudos de casos empíricos.

As empresas destinatárias do pedido de disclosure do CDP/Investidores selecionadas para esta pesquisa são empresas de grande porte e foram escolhidas com base na classificação criada pela BM\&FBOVESPA. As empresas pertencem a 12 setores produtivos, mas apenas dez participaram da pesquisa. Os setores foram: Construção \& Transporte (ALL); Indústria de Alimentos (JBS); Serviços (Odonto Prev); Financeiro (Banco do Brasil); Indústria de bens/equipamentos (Microinox); Petroquímicas (Braskem); Siderurgia/Metalurgia (Arcelor Mittal); Papel e Celulose (Fibria); Petróleo \& Gás e Biocombustíveis (Petrobras); e Utilidade pública (CESP).

É possível concluir que as empresas brasileiras signatárias do $\mathrm{CDP} /$ Investidores vão ao encontro do entendimento que a sociedade e as instituições têm sobre os problemas acarretados pelas mudanças climáticas geradas pela ação humana.

Quanto às estratégias de legitimidade de Suchman (1995), constatou-se que a legitimidade pragmática e o critério ganho obtiveram o maior número de citações, respectivamente 377 e 495. O item mais citado em todos os casos ilustrativos foi responder às necessidades dos stake- 
holders, com 335 evidenciações. Com isso, pode-se afirmar que as empresas estão preocupadas em atender às necessidades do seu público de interesse e focadas na percepção desse público sobre suas atividades, visando ao ganho de legitimidade.

Em relação à legitimidade moral, o critério manutenção conseguiu a maior quantidade de citações (76), e os itens mais citados foram monitorar a responsabilidade e comunicar oficialmente.

Por fim, na legitimidade cognitiva, destacou-se o critério ganho, com 74 evidenciações, e os itens mais destacados foram: formalizar as operações, padronizar as operações, popularizar modelos e buscar certificação perante órgãos reguladores. Esses resultados indicam que as empresas estão buscando realizar suas atividades dentro de padrões e normas estabelecidos, visando aumentar sua legitimidade e, portanto, diminuindo a possibilidade de ocorrerem falhas no processo, o que poderia resultar em ações para recuperar a legitimidade.

Pautando-se nas estratégias de legitimidade propostas por Suchman (1995), a pesquisa demonstrou que os casos 1 e 4, respectivamente as empresas Petrobras e JBS, apresentaram o maior número de evidenciações. Entretanto, a Petrobras destacou-se por possuir o maior número de evidenciações da estratégia de legitimidade pragmática e do critério ganho.

Dessa forma, infere-se que as empresas analisadas reconhecem as oportunidades e os riscos das mudanças climáticas - regulatórios, físicos, mercadológicos e reputacionais - no que concerne aos impactos em seus negócios. Nesse sentido, estão num contínuo processo de busca de legitimação e implementação de ações para reduzir as emissões de GEE. Ademais, é possível concluir que as empresas analisadas vêm desenvolvendo ações para obter aceitação e legitimidade perante as suas partes interessadas.

A presente pesquisa, todavia, demonstrou algumas limitações, devido à subjetividade na análise de conteúdo, com interpretações e decodificações pessoais por parte dos pesquisadores. O disclosure no site do CDP foi um disclosure parcial, e as dificuldades para obter as respostas das empresas ao questionário da pesquisa fizeram com que dois setores estratégicos (telecomunicações e mineração) não fossem objeto dos casos empíricos. Outro limitante é a estratégia de pesquisa de estudo multicaso, a qual não permite fazer generalizações.

Considerando essas limitações da pesquisa, recomenda-se como estudos futuros: comparar as estratégias de legitimidade utilizadas por cada setor produtivo destinatário do CDP (tipo de riscos e oportunidades, a estrutura de capital, o grau de sensibilidade ambiental e se pertence a setor regulado), bem como investigar o processo de institucionalização de outras práticas de carbon disclosure no Brasil. Quanto à metodologia, sugere-se o uso combinado de abordagens qualitativas e quantitativas e a realização de estudos comparativos entre os países do BASIC (China, Índia, África do Sul e Brasil) em relação às estratégias de legitimidade adotadas por empresas desses países destinatárias do pedido de carbon disclosure do CDP. 


\section{REFERÊNCIAS}

América Latina Logística. Site institucional. Disponível em: <http://www.all.com.br>. Acesso em: 10 jan. 2013.

ARCELOR Mittal Brasil. Site institucional. Disponível em: <http://www.arcelor.com.br>. Acesso em: 10 jan. 2013.

BANCO DO BRASIL. Site institucional. Disponível em: <http://www.bb.com.br>. Acesso em 10 jan. 2013.

BARDIN, L. Análise de conteúdo. Lisboa: Edições 70, 2009.

BEUREN, I. M.; GUBIANI, C. A.; SOARES, M. Estratégias de legitimidade de Suchman evidenciadas nos relatórios da administração de empresas públicas do setor elétrico. Rev. Adm. Pública, Rio de Janeiro, v. 47, n. 4, p. 849876, jul./ago. 2013.

BRASKEM. Site institucional. Disponível em: <http://www.braskem.com.br>. Acesso em: 10 jan. 2013.

CARBON DISCLOSURE PROJECT. Brasil. Disponível em: <http://<www.cdproject.net>. Acesso em: 10 dez. 2010.

Companhia Energética de São Paulo. Site institucional. Disponível em: <http://www. cesp. com.br>. Acesso em: 10 jan. 2013.

CORMIER, D.; Gordon, I. M.; Magnan, M. Corporate Environmental Disclosure: contrasting management's perceptions with reality. Journal of Business Ethics, v. 49, n. 2, p. 143-165, 2004.

DIAS FILHO, J. M. A pesquisa qualitativa sob a perspectiva da Teoria da Legitimidade: uma alternativa para explicar e predizer políticas de evidenciação contábil. In: Encontro Nacional da Associação Nacional de Pós-Graduação e Pesquisa em Administração, 32., 2008, Rio de Janeiro. Anais... Rio de Janeiro: EnANPAD,
2008. p. 1-9.

Políticas de evidenciação contábil: um estudo do poder preditivo e explicativo da teoria da legitimação. In: Encontro Nacional da Associação Nacional de Pós-Graduação e Pesquisa em Administração, 31., 2007, Rio de Janeiro. Anais... Rio de Janeiro: EnANPAD, 2007. p. 1-11.

DEEGAN, C.; RANKIN, M.; VOGHT, P. Firms' disclosure reactions to major social incidents: Australian evidence. Accounting Forum, v. 24, n. 1, p. 101-130, Mar. 2000.

DOWLING, J.; PFEFFER, J. Organizational legitimacy: social values and organizational behavior. Pacific Sociological Review, v. 18, $n$. 1, p. 122-136, 1975.

JBS. Site institucional. Disponível em: <http:// www.jbs.com.br>. Acesso em: 10 jan. 2013.

fgv. Registro público de emissões de GEE do país. Disponível em: <http:www.fgv.br/ces/ registro>. Acesso em: 22 abr. 2012.

FARIAS, L. G. et al. Mercado global de carbono e governança global do clima: desafios e oportunidades. Desenvolvimento e Meio Ambiente, Curitiba: Ed. da UFPR, v. 28, p. 1127, jul./dez. 2013.

FANK, O. L.; BEUREN, I. M. Evidenciação das estratégias de legitimidade da tipologia de Suchman (1995) nos Relatórios da Administração da Petrobras. Revista de Contabilidade e Administração, Ribeirão Preto: FEA-RP/USP, v. 4 , n. 10 , p. $25-47$, set./ dez. 2010.

GIDDENS, Anthony. A política da mudança climática. Rio de Janeiro: J. Zahar, 2010.

GRAY, R.; KOUHY, R.; LAVERS, S. Corporate Social and Environmental Reporting: a review of the literature and a longitudinal study of UK disclosures. Accounting, Auditing \& Accountability Journal, v. 8, n. 2, p. 47-77, 1995. 
LINDBLOM, C. The implications of organizational legitimacy for corporate social performance and disclosure. Presented at Critical Perspectives on Accounting Conference, New York, 1994.

MACHADO, D. P. A evidenciação ambiental como instrumento de gestão da legitimidade social em empresas brasileiras de capital aberto. 2014. 105 f. Dissertação (Mestrado em Contabilidade) - Universidade do Vale do Rio dos Sinos, São Leopoldo, 2014.

MAHADEO, J. D.; OOGARAH-HANUMAN, V.; SOOBAROYEN, T. Changes in social and environmental reporting practices in an emerging economy (2004-2007): exploring the relevance of stakeholder and legitimacy theories. Accounting Forum, v. 35, p. 158-175, 2011

MEYER, J. W.; ROWAN, B. Institutionalized organizations: formal structure as myth and ceremony. American Journal of Sociology, v. 83, n. 2, p. 340-363, 1977.

MICROINOX. Site institucional. Disponível em: $<$ http://www.microinox.com.br>. Acesso em: 10 jan. 2013.

ODONTOPREV. Site institucional. Disponível em: <http://www.odontoprev.com.br>. Acesso em: 10 jan. 2013.

O'DONOVAN, G. Legitimacy theory as an explanation for corporate environmental disclosures. 2000. $441 \mathrm{f}$. Tese (Doutorado)Victoria University of Technology, 2000.

PATTEN, D. M. Intra-industry environmental disclosures in response to the Alaskan oil spill: A note on legitimacy theory. Accounting, Organizations and Society, v. 17, n. 5, p. 471475, 1992.

ROSA, A. R.; COSER, C. A abordagem institucional na administração: a produção científica brasileira entre 1993 e 2003. In: Seminário de Gestão de Negócios - FAE Business School, 1., 2004, Curitiba. Anais...
Curitiba, 2004. p. 1-21.

ROSSONI, L. Que é legitimidade organizacional? In: Encontro de Estudos Organizacionais da ANPAD, 7., 2012, Curitiba. Anais... Curitiba: Eneo, 2012. p. 1-11.

ROSSONI, L.; TEIXEIRA, R. M. A interação dos relacionamentos com os recursos e a legitimidade no processo de criação de uma organização social. Cadernos EBAPE.BR, v. 6, n. 4, p. 1-19, 2008.

RIBEIRO, M. S.; SOUZA, V. R. Aplicação da contabilidade ambiental na indústria brasileira. Revista de Contabilidade e Finanças da USP, v. 15, n. 35, p. 54-67, 2004.

PETROBRAS. Site institucional. Disponível em: <http://www.petrobras.com.br>. Acesso em: 10 mar. 2012.

Sampaio, M. S et al. Evidenciação de informações socioambientais e isomorfismo: um estudo com mineradoras brasileiras. Revista Universo Contábil, v. 8, n. 1, p. 105122, jan./mar. 2012.

SUCHMAN, M. Managing legitimacy: strategic and institutional approaches. Academy of Management Review, v. 20, n. 3, p. 571-610, Jul. 1995.

VIOLA, E.; LEIS, H. R. Governabilidade e mudança climática: desafios e impasses globais e brasileiros. Idéias - Revista do Instituto de Filosofia e Ciências Humanas, Campinas: Unicamp, ano 8 (2), n. 2, p. 71-114, 2001.

THOMAS, T. C.; LAMN, E. Legitimacy and organizational sustainabilitu. Journal Business Ethics, v. 110, n. 2, p. 191-203, 2012. 